\title{
Effect of Federal Policy Changes on International Students Pursuing Higher Education Studies in the United States
}

\author{
James McKivigan \\ Department of Physical Therapy, Touro University, Nevada, Henderson USA \\ Email address: \\ James.mckivigan@tun.touro.edu \\ To cite this article: \\ James McKivigan. Effect of Federal Policy Changes on International Students Pursuing Higher Education Studies in the United States. Higher \\ Education Research. Vol. 5, No. 2, 2020, pp. 60-67. doi: 10.11648/j.her.20200502.14
}

Received: April 13, 2020; Accepted: May 6, 2020; Published: May 15, 2020

\begin{abstract}
Background: In 2018, President Donald J. Trump announced that his administration would place restrictions on international students seeking to pursue higher education degrees in the United States. American institutions of higher education protested these policy changes, because international students represent a significant social and cultural contribution to their system and provide a source of revenue. The restrictions on international students were not overwhelming, primarily consisting of increased visa fees and threats stating that misbehavior in the country would result in immediate deportation. Although these demands do not typically deter international students, some individuals view these restrictions as part of an overall trend of anti-immigrant sentiment in the United States. The goal of this study was to investigate the impact of these new restrictions on the education of international students in the United States. Methods: The population, intervention, comparison, and outcome (PICO) question format was used to formulate the research question, centered on international students seeking to complete their higher education in the United States. The databases used for this study were ProQuest, JSTOR, LexisNexis, and Google Scholar. Results: The movement to place restrictions on international students in the United States is a recent development, and no statistically significant effects can presently be determined. Government funding for public universities, who market their programs to international students, has been reduced. Conclusions: This research demonstrates that international student attendance at American universities was declining before the immigration restrictions were implemented. Based on current data, it is too early to determine how immigration restrictions will impact American universities, and more time will be needed to evaluate the impact of President Trump's policies.
\end{abstract}

Keywords: International Students, Student Visas, Trump Immigration Policies, United States Universities

\section{Introduction}

For decades, the United States has been a leading destination for international students and researchers. However, according to the National Association of Foreign Student Advisers (NAFSA), the 2018-2019 academic years revealed a nearly $10 \%$ reduction in the number of recently enrolled international students in the US [5]. It has been hypothesized that one possible cause of this reduction may be changes to US visa policy, due to policy changes enacted by the Trump administration. Since taking office in 2017, President Donald J. Trump has taken an aggressive stance against immigration, holding to one of the major promises made to his political base during his presidential campaign. In addition to his drawn-out fight for a border wall and his practice of detaining undocumented immigrants for unspecified lengths of time, President Trump has also significantly limited the number of US visas issued each year, including visas issued to international students [38].

Although the number of visas issued to international students has not been drastically reduced, and nor have international students been banned from entry, nonetheless it is important to recognize that increasingly tight restrictions and bureaucratic rules have been applied to students seeking these documents. According to Kang et al., because of the recent revisions in immigration policy, international students are confronting increased organizational barriers that are either currently in effect or projected [13]. Such restrictions include increased application fees and altered consequences for students who breach visa requirements. This situation also applies to infringements that are committed unintentionally. The cost of application fees has increased as additional means 
have been implemented to penalize students who fail to meet visa conditions. Moreover, tuition fees at US universities are at an all-time high. Although the cost to attend private universities is usually the same for both international and domestic students, nonetheless the general cost is significantly higher for international students, because they must typically pay hidden fees, such as "international student fees" and Student and Exchange Visitor Information System (SEVIS) fees [35]. There has also been an increased examination of programs that allow students to work in the United States after graduating from college.

In addition to these new fees and requirements, the increase of xenophobia and anti-immigrant sentiment in the United States has had a significant effect on international students seeking to pursue courses of study at American universities $[14,33,38]$. These potential students worry that they may have their visas revoked and be deported for relatively minor infractions, such as jaywalking or being involved in a traffic accident. They also fear that their visas may be revoked without cause at any point during their educational programs [13]; after all, such instances have occurred, in which students commence a bachelor's, master's, $\mathrm{Ph}$. D., or other professional degree program but are later forced to disenroll and return home before they have completed their studies.

Additionally, these students worry that they may face persecution and police harassment due to their status as an international citizen [12]. For example, an F-1 student visa is a nonimmigrant visa that implies almost no guarantees from, or the good graces of, the United States and provides little or no protection to students who encounter legal trouble. It has been reported that the social and political environment $(60 \%)$ and the lack of feeling welcome in the United States (48.9\%) are factors contributing to the declining number of new international students. Colleges and universities also cite a significant increase in concerns for physical safety, including gun violence and civil unrest [5].

Many American universities and colleges are already reporting a significant decrease in the number of applications submitted by international students [25]. The higher education system in the United States may suffer substantially from the significantly reduced enrollment of international students. For many public American universities and colleges, international students represent a significant source of revenue, because they are charged a considerably higher tuition rate than United States citizens. In addition, international students do not qualify for federal student aid packages due to their citizenship status. Thus, in reality, international students are an infusion of revenue into the national economy and not the liability that they have been portrayed as in national political rhetoric [9-11].

Moreover, the loss of international students means that American students will lose the opportunity to be exposed to peers from nations and cultures that differ from their own. The current loss of international students and the noted decline in enrollment represent a complex problem for the higher education system within the United States.

While much editorial content has been published regarding the problems associated with a potential shortage of international students in the United States, there has not yet been a systematic review of the literature on causes associated with President Trump's policies. This paper will conduct a systematic review of the scholarly research that has been published within the last five years, with the aim of providing a more empirical view of the impact exerted by the guidelines of the Trump administration on the enrollment of international students within the United States.

\section{Methods}

\subsection{Formulation of the Research Question}

The population, intervention, comparison, and outcome (PICO) format was used to develop a research question, followed by a systematic literature review on the topic. This format is typically used in the field of nursing science but is also useful for the current topic under investigation. Supported by the literature, we expected that dividing the question into four components would aid in identifying the relevant information [4]. According to Kang et al., the PICO system can be applied to reduce and divide evidence into keywords that can be easily researched [18]. The system also aids in the formulation of research questions. Some researchers find that this system requires demanding technical skills, while others may find the system time-consuming or challenging to learn. For this work, the procedure facilitated the extraction of retrievable evidence and allowed an appraisal of that information.

For this topic, the population in question consists of international students seeking to complete a program of higher education within the United States. The intervention is the various policies enacted by the Trump administration that created new barriers for international students to obtain and maintain their student visas for study in the United States. The comparison factor is what may have occurred had the Trump administration not introduced policies to restrict international student visas for study in the United States. The outcome factor is the actual impact of these restrictions on institutions of higher education within the United States. The PICO-based research question that this literature review seeks to answer is twofold: How has the declining enrollment of international students reported by US universities since the implementation of the Trump policies affected universities and colleges within the United States? What might be the extended consequences of this decline?

\subsection{Inclusion Criteria}

To identify the appropriate literature for this topic, several major academic research databases were utilized, including ProQuest, JSTOR, LexisNexis, and Google Scholar. The main keyword phrases included "international students in the United States," "Trump immigration policies and international students," and "student visa restriction in the United States." The primary inclusion criteria used for this search were peer-reviewed academic journals published in the English language within the last five years. Furthermore, the articles 
were required to deal solely or primarily with international students in the United States (the issue of international students and visa restrictions has also been a controversial topic in the United Kingdom and Australia).

\subsection{Exclusion Criteria}

Articles retrieved by the search were excluded if they were not published in the English language or were published before 2015. Moreover, articles that did not appear to be peer-reviewed. Another strict exclusion criterion was applied to address the numerous academic articles dealing with immigration and international students from the British and Australian perspectives. Because this paper seeks to investigate solely the effect of President Trump's immigration policies on international students in the United States, it was necessary to exclude articles that approach this matter from a British or global perspective.

\section{Results and Discussion}

One key field of study in migration research is related to international student mobility and migration, which has increased significantly over the past decades both in numbers and in political, economic, and academic significance. Many receiving countries facilitate education-to-work transitions for international students after graduation, which allows nations to fill skill shortages with locally trained international students [27].

Overall, the recent restrictions on international student visas in the United States represent a new phenomenon, and it is too early to discern any statistically significant trends related to the challenges faced by international students within the United States.

Moreover, the current state of student visa restrictions within the United States is limited to heightened fees and bureaucratic hurdles. Because many international students seeking to pursue educational programs within the United States are from financially affluent backgrounds, these fees and restrictions do not yet appear to present a hindrance. This trend may be due to programs such as optional practical training (OPT) programs that present alumni with a temporary work visa, provided that their work is within their field of study. For science, technology, engineering, and mathematics (STEM) degree recipients, the United States extended the OPT visa to 29 months in 2008 and 36 months in 2016. This process increased the number of foreign-trained graduates by approximately $400 \%$ [30]. However, according to Altbach and Reisberg, international students are facing new challenges due to unpredictable changes in immigration regulations for several major countries in which they had previously been welcomed [1]. In some English-speaking countries, notably the United States, immigration regulations have undergone significant recent changes in policy. In some instances, international students have been a focus of these changes. The changes have altered the model of international student opportunities and limited the number of students who can apply for enrollment. Of course, these decreases in student numbers may indicate a slowing of the previous increase in international students applying for enrollment in American universities.

Indeed, the increasing enrollment of international students at American universities and colleges was a fragile "bubble" that required little effort to burst. After decades of expansion, the statistics have shifted. The number of university students, the growth of tuition costs, and the total number of colleges are decreasing or growing more slowly. The annual increase in college tuition is at its lowest rate, the annual growth rate of student debt is lower, and the number of college enrollees has declined for five consecutive years. Altogether, the figures clearly indicate that the higher education market is declining [37].

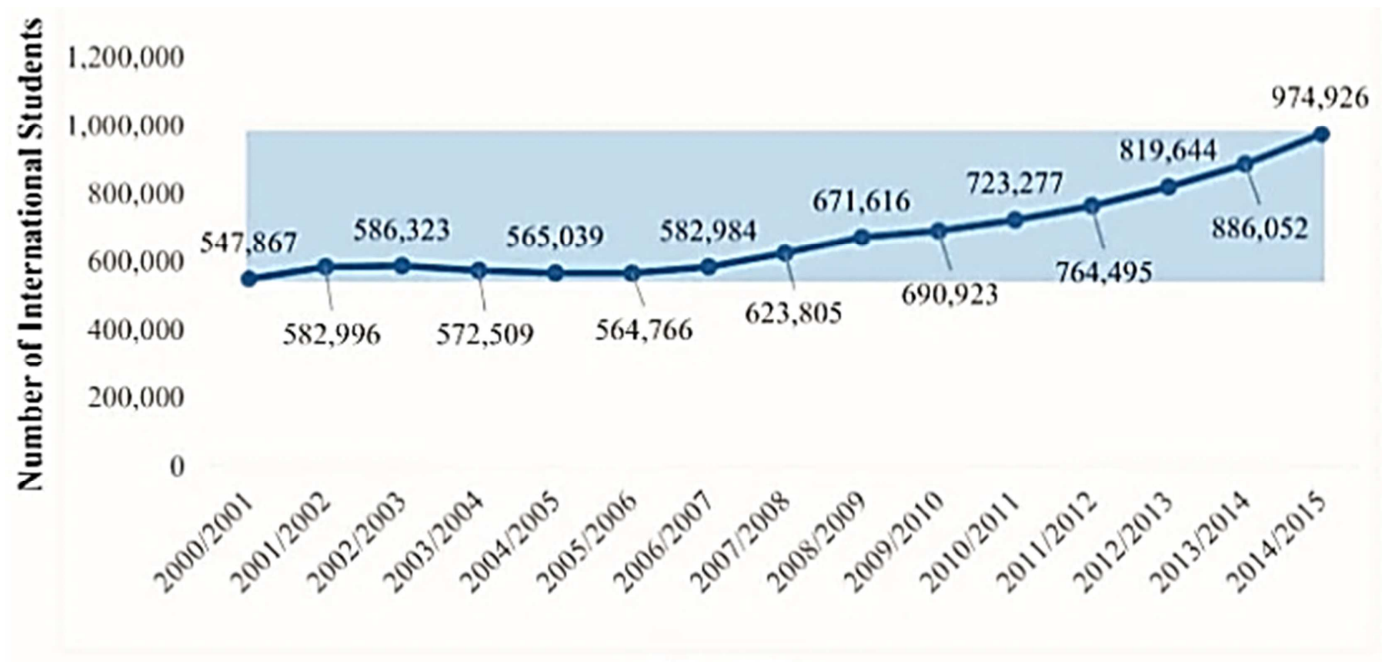

School Year

Figure 1. International student enrollment trend in American universities and colleges from 2000/2001 to 2014/2015.

To compensate for the revenue losses that have resulted as state and federal legislatures have significantly reduced or 
eliminated funding for public universities, higher educational institutions have been aggressively marketing their programs to international students. These students can be justifiably charged a significantly higher tuition rate than domestic students, and international students are often able to pay these fees without having to request financial aid or scholarship packages [40]. Indeed, the international student community has responded well to these marketing efforts, as demonstrated in Figure 1. Nonetheless, this shift in international student enrollment may represent a short-lived era already nearing its end. Many international students complain that they are not provided with sufficient educational support at American universities (which is often significantly lacking, especially for students who speak English as a second language), and such students may feel isolated and marginalized on campus. Altbach and Reisberg reported that international student enrollment was already entering a decline when President Trump announced his 2019 policies. Thus, these new immigration policies may jeopardize this already tenuous system [1].

As another potential result of the most recent student immigration restrictions, many of these students may opt for academic career paths with the hope of protecting the length of their stay in the United States and increasing the likelihood that they will be able to remain once they finish their educational program. However, this phenomenon is not solely due to the Trump administration's policies but is also due to restrictions on H1-B visas that began as early as 2004, during President George W. Bush's administration. According to Amuedo-Dorantes and Furtado, the H1-B visa limit that went into effect in 2004 resulted in increased difficulty for many foreigners seeking employment in the United States [2]. Of course, there were exclusions in several sectors, such as not-for-profit education and some research institutions.

The fact that international students are opting for strictly academic career paths to maintain their visa standings is significant. For the last two decades, the higher education job market in the United States has been on a steep decline. Estimates conclude that more than $70 \%$ of all job openings within this sector are for "contingent faculty" or "adjunct professor" positions, all of which offer comparatively low wages, few to no benefits, and almost no job security [39]. Among the international students who come to the United States, many of whom are already independently wealthy or actively benefiting from intergenerational wealth within their nations of origin, the low wages offered by these positions may not be of great concern. Moreover, for an international academic who must provide proof of stable, secure employment to maintain their legal residency within the United States, an academic career path may be desirable. This situation may also cause international students to delay seeking employment [9]. Although such a choice may guarantee the security of these students' educational programs, nonetheless such individuals may find themselves in significant jeopardy when they are unable to secure a permanent university faculty position.

Moreover, both the American economy and society are negatively impacted when highly talented young scientists or scholars choose an academic path (i.e., the "ivory tower") over a career in technology or industry. On the one hand, the image of eccentric scholars who are isolated and disinterested in the surrounding real world and the idea of the ivory tower may seem like clichés today, because many efforts have been made to ensure that universities contribute to regional economic development; on the other hand, it appears that academics cannot escape this well-established stereotype [20]. Such efforts include the development of technology transfer offices, incubators, entrepreneurship, and professors. To develop these systems, higher education institutions need more advisory and support services in different fields, such as industry cooperation, patenting, and start-ups. Key persons at universities should support these interconnections, and start-up ideas that originate with students in classes should be further developed and assessed. Postdoctoral researchers will always be an essential and productive group of employees in academia. The lack of further career prospects and embeddedness within their organizations can be a significant issue for the future of these researchers and their institutions. As long as an adverse climate surrounds the future of postdocs in academia, market-oriented careers present another option for international students after they complete their $\mathrm{Ph}$. $\mathrm{D}$.

Another critical negative impact of the recent student immigration restrictions may be a net loss of talent for the United States labor force. In many instances, international students who have a positive experience in their host country opt to remain and pursue permanent residency and citizenship. As argued by Manuel, who explicitly discussed issues related to Vietnamese students pursuing educational degree programs within the United States, international students whose countries of origin have high degrees of political, social, and economic instability tend to want to remain in hospitable host countries [21]. These students feel that they can contribute significantly to the host nation's economy, society, and culture. When international students are made to feel unwelcome in a host country, they feel marginalized. As a consequence, these students are less likely to remain in the nation after completing their degree programs and do not "give back" to the host countries once they have finished their education.

Another major problem that may arise for both the United States as a nation and the American higher education system as a result of the recent student immigration restrictions imposed by President Trump is a global decline in the prestige typically associated with the higher educational system here in the United States. Banjong and Olson reflected on the aspects that attract the most substantial proportion of international students to the US [6]. In general, students are driven from their home countries to obtain an education abroad through several economic and social forces. The choice of the country and university to which the student emigrates and matriculates, respectively, is often driven by numerous factors. The country that international students choose for study depends on several "pull" features. Mazzarol and Soutar defined these aspects using a so-called push-pull paradigm, where "push" signifies factors forcing students from their home countries and "pull" 
characterizes factors enticing students to countries in which they can pursue their education [23]. Figure 2 demonstrates trends in enrollment of international students in the US. The majority of international students may come from developing countries, pushed by the insufficient supply and poor quality of education in these nations. Demographic features such as age, marital status, nationality, and source of financial support influence international students' choices and travel activities.

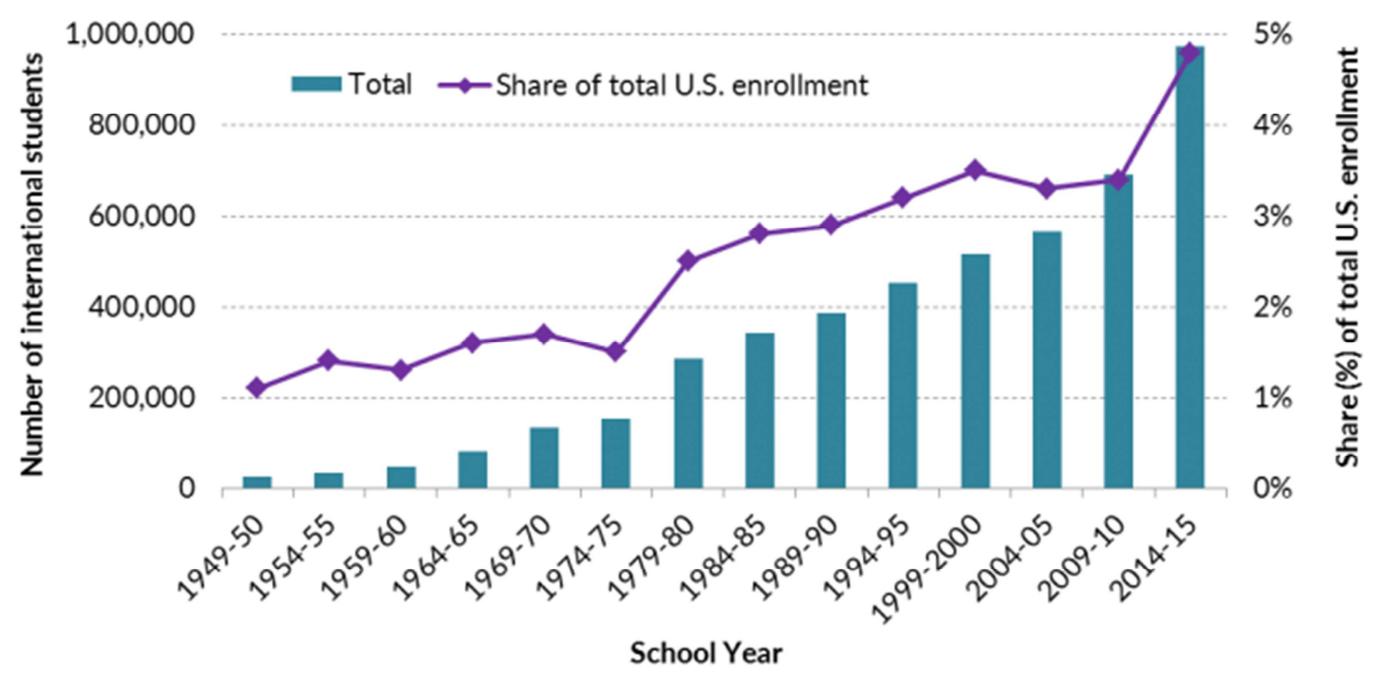

Figure 2. Trends in international students enrolled in American universities and colleges and their share (\%) of total US higher education student enrollment over time.

Currently, there are few existing datasets regarding the precise impact of the Trump administration's restrictions on student visas, because these restrictions have simply been too recent to characterize effectively. Growing evidence shows that these restrictions are adding to a culture of xenophobia and anti-immigrant sentiment that has been increasing in the United States over time and that became more prominent with the election of President Trump in 2016 $[15,17]$. Although many variables influence international enrollments, the reduction in new students comes at a time when many have voiced fears that President Trump's rhetoric and policies could discourage some international students from enrolling at US institutions [29]. The current limitations on international students in the United States are only part of a larger, highly negative trend that has been growing within the United States for years, which is perhaps the most disconcerting aspect of these new restrictions. More specifically, after years of expansion, enrollments of international students at American universities started to level off in fall 2016, with nearly half of the universities surveyed reporting a decrease in new international students in 2017 [25]. The most selective universities continued to report growth in new international student enrollments, with the top three most selective US universities reporting the following statistics: Harvard University enrolled $12.8 \%$ international students; Stanford University enrolled 11.4\% foreign citizens, representing 60 countries for the 2018 academic year; and Yale University reported $11.8 \%$ international students representing 123 countries in the 2018 academic year. Masters-level institutions have reported the steepest declines (approximately 20\%) in new international enrollments. Institutions in the middle of the country, including the West South Central region, showed steeper declines in new registrations than institutions on the East and West Coasts. Science and engineering fields saw a $6 \%$ decrease in international graduate students from 2016-2017. This reduction primarily resulted from Indian students, whose enrollments fell by $19 \%$ in 2017 . Fewer students also matriculated from South Korea, Iran, and Saudi Arabia in 2017. Because many factors can influence a one-year decrease, these figures, which have continued since 2017, may be represent an overall trend. However, the reported concerns of Indian students planning to attend graduate school in the next few years suggest that this decrease might be more important than first thought. When interviewed by The World, these students expressed their concern that with changing immigration guidelines under the current US administration, they may not be able to obtain employment after graduation, leaving them in debt to the US school system. Most are deterred by the high costs of pursuing a degree in the US, but some are worried about their safety as well. Many students are considering Canada, Australia, Germany, and the UK as potential host countries for graduate programs as a substitute to the US.

As multiple studies have demonstrated, there are significant problems within the framework of United States immigration law, as well as in the manner in which it is enforced $[7,22]$. First, almost all immigrants targeted by Trump's executive order have been Hispanic. Because immigrants from Latin America do not comprise the whole of the current population of illegal immigrants, this focus points to a fundamentally racist system. Moreover, news reports have come from all over the United States of Hispanic Americans who are in the US legally, or their families, and yet are being targeted by US Immigration and Customs Enforcement (ICE) or by Border Patrol agents because of their outward appearance or because 
they bear a Spanish surname. For example, individuals who speak Spanish in public or who speak English with a "Hispanic" accent have been subject to scrutiny [8]. These incidents point to the high likelihood that President Trump's executive order was targeted directly at Latin American immigrants in the United States. Furthermore, when considering President Trump's inflammatory rhetoric regarding Mexico and "building a wall and making them pay for it" during his presidential campaign, one might speculate that these deportations and shakedowns are, in large part, showboating by the Trump administration to pander to the voter base, a substantial segment of which bears an irrational hatred toward people of Hispanic descent [8].

It is significant that more than $50 \%$ of the upsurge in the US population between 2000 and 2010 was a result of growth in the Hispanic community. By 2016, Hispanics in the United States numbered 57.5 million (17.9\%), making them the most significant ethnic or racial minority in the United States. The growth in the Hispanic population has also been accompanied by an increase in the Hispanic student population. Hispanic students now account for $22.7 \%$ of all students enrolled in higher education, with Mexico being ranked ninth as the top countries of origin of international students [26]. After increasing by 0.7 million in the years from 1996 to 2006, the college enrollment of Hispanics increased by 1.7 million from 2006 to 2016. Data on the education of Mexican migrants from 1996 to 2012 have shown that more educated migrants are now migrating to the US. The population with $10-12$ years of schooling has increased from $27.5 \%$ to $37 \%$, while that of migrants with 9 years of education or less has decreased from $60.2 \%$ to $47 \%$ [24]. Mexican migrants continue to be less educated than Asian migrants, although the overall Hispanic population is becoming more educated. New immigration policies, however, can impact the presence of depression, anxiety, and trauma and can serve to exacerbate the sense of discrimination that is felt across Latino families, which can lead to fear and mistrust. This rising adverse climate can have a considerable impact on Hispanic international students, who represent a high percentage of US university students. Long-term follow-up is needed to assess the actual impact of the Trump administration's politics on Hispanic students; fortunately, a significant amount of research has been performed regarding their enrollment in US universities.

The decline in international student enrollment may influence essential opportunities for the exchange of academic and cross-cultural knowledge [3]. Interactions with individuals from other countries and cultures can benefit students and researchers by cultivating new perspectives and ideas, both personally and professionally. Moreover, studying abroad can help students in embracing global perspectives, expanding global awareness, gaining new insights, and developing skills that increase employability after college [16].

In addition to the highly publicized cases on the abuse of immigrants and contempt for international individuals within the United States, the recent additional restrictions placed by President Trump upon student visas may be an indicator that future policies and rhetoric will only become more anti-immigrant. If the United States government is unwilling to accept international individuals who simply admire the American system of higher education and want to make better lives for themselves, the whole American system will suffer. Since 1900, immigrants have represented one-third of the US recipients of Nobel Prizes in chemistry, physics, medicine, and economics, and immigrants are responsible for more than $25 \%$ of the approximately 110,000 patents filed in the United States each year [19]. Several Americans awarded Nobel Prizes in chemistry, physics, and economics are immigrants. These recipients are Americans by choice, but not by birth. Other past notable winners, including Albert Einstein, only established American citizenhood after winning their awards $[28,31]$.

There has been concern that with a high international student enrollment, fixed resources become diluted among the larger populace and lead to the displacement of domestic students. However, at the graduate level, it has been shown that international students do not inhibit but increase local enrollment. Such positive effects are attributable to cross-subsidization, whereby international student tuition revenue is used to subsidize the cost of enrolling additional domestic students [32]. It has also been shown that efforts to limit nonresident enrollment based on fears of domestic displacement may be misguided [34]. A significant number of studies have demonstrated that international students positively contribute to research and innovation, and it has been suggested that such benefits may not come at the expense of domestic students [36].

Generally, international students have represented a net benefit for American society. They are charged much higher tuition rates than domestic American students and do not ask for financial aid or student loans. They typically exhibit good behavior when in the United States and often remain in the country upon completion of their degree programs, making substantial contributions to American society. The more than one million international students in US universities represent approximately $5 \%$ of enrollees and provide an estimated annual stimulus of US \$39 billion to the economy [19]. As discussed in this article, the recently imposed restrictions will be highly destructive to the United States, both as a society and as a system of higher education. The results of this literature search strongly suggest that although the international student "bubble" was already showing signs of bursting when President Trump announced his intentions with new policy, nonetheless the new conditions will create further problems. Such problems include international students arbitrarily opting for precarious careers in academia and an overall decline in revenue for American universities and colleges. There may also be a deterioration in the public image and international prestige of the United States.

\section{Conclusion}

As demonstrated by a thorough literature review, it is still too early to determine whether the recent immigration 
restrictions imposed on international students by President Trump have exerted a measurable impact on corresponding enrollment at American universities or have impacted the quality of their educational experiences in the United States. The restrictions were implemented in mid-2018, and most are not draconian; instead, most of these new student visa restrictions come in the form of increased fees, lengthier security checks, and stricter behavioral requirements during the student's stay. Moreover, this systematic literature review indicates that international student enrollments in American universities and colleges were already declining when President Trump signed this order. It appears that there was indeed an "international student bubble" that began approximately two decades ago, when United States universities and colleges began to seek a replacement for the public revenue that was being lost. That bubble was already starting to burst in 2018. However, these new restrictions are part of what has been labeled the "dark ages" of policy toward all immigrants, which is the most distressing aspect of these changes.

\section{References}

[1] Altbach, P. G., \& Reisberg, L. (2017). Global: Another week, another scandal: immigration dilemmas and political confusion. In Understanding higher education internationalization (pp. 103-106). Sense Publishers. https://doi.org/10.1007/978-94-6351-161-2_22.

[2] Amuedo-Dorantes, C., \& Furtado, D. (2019). Settling for academia?: H-1B visas and the career choices of international students in the United States. Journal of Human Resources, 54 (2), 401-429. https://doi.org/10.3368/jhr.54.2.0816.8167R1.

[3] Arthur, N. (2017). Supporting international students through strengthening their social resources. Studies in Higher $\begin{array}{llll}\text { Education, } & 42 & \text { (5), } & \text { 887-894. }\end{array}$ https://doi.org/10.1080/03075079.2017.1293876.

[4] Aslam, S., \& Emmanuel, P. (2010). Formulating a researchable question: A critical step for facilitating good clinical research. Indian Journal of Sexually Transmitted Diseases and AIDS, 31 (1), 47. https://doi.org/10.4103/2589-0557.69003.

[5] Association of International Educators. (2019). Loosing talent. Retrieved February 22, 2020, https://www.nafsa.org/sites/default/files/media/document/nafs a-losing-talent.pdf.

[6] Banjong, D. N., \& Olson, M. R. (2016). Issues and trends of international students in the United States. International Journal of Education, 4 (1), 1-14.

[7] Bier, D. J. (2019). Legal immigration will resolve America's real border problems. Cato Institute. https://doi.org/10.36009/PA.879.

[8] Calvin, H. (n. d.). Volume 28 (2017-18) - Asian American Policy Review. Retrieved February 22, 2020, from https://aapr.hkspublications.org/print/vol28/.

[9] Cantwell, B. (2015). Are international students cash cows? Examining the relationship between new international undergraduate enrollments and institutional revenue at public colleges and universities in the US. Journal of International Students, 5 (4), 512-525. http://jistudents.org.

[10] Chellaraj, G. (2019). The Economics of International Student and Scholar Mobility: Directions for Research (pp. 1-42).

[11] Choudaha, R. (2019). Beyond $\$ 300$ billion: The global impact of international students. Retrieved February 22, 2020, from https://www.studyportals.com/wp-content/uploads/2019/08/B eyond_300b_International_Students_Final-Aug15.pdf.

[12] Ee, J. (2013). "He's an idiot!" Experiences of international students in the United States. Journal of International Students, 3 (1), 72-75. Retrieved from https://www.ojed.org/index.php/jis/article/view/522.

[13] Federis, M. (2019, June 20). US visa rules are restricting the future of international students. Global National Education. Retrieved February 15, 2020, from https://www.pri.org/stories/2019-06-20/visa-rules-are-restricti ng-future-international-students-us.

[14] Hainmueller, J., \& Hopkins, D. J. (2014). Public attitudes toward immigration. Annual Review of Political Science, 17 (1), 225-249.

https://doi.org/10.1146/annurev-polisci-102512-194818.

[15] Hou, F., \& Lu, Y. (2017). International students, immigration and earnings growth: The effect of a pre-immigration host-country university education. IZA Journal of Development and Migration, 7 (1), 5. https://doi.org/10.1186/s40176-017-0091-5.

[16] Jackson, M., Ray, S., \& Bybell, D. (2013). International students in the U.S.: Social and psychological adjustment. Journal of International Students, 3 (1), 17-28. Retrieved from https://www.ojed.org/index.php/jis/article/view/515.

[17] Jamaludin, N. L., Sam, D. L., Sandal, G. M., \& Adam, A. A. (2018). The influence of perceived discrimination, orientation to mainstream culture and life satisfaction on destination loyalty intentions: The case of international students. Current Issues in Tourism, 21 (8), 934-949. https://doi.org/10.1080/13683500.2015.1119102.

[18] Kang, T., Zou, S., \& Weng, C. (2019). Pretraining to recognize piCO elements from randomized controlled trial literature. Studies in Health Technology and Informatics, 264, 188-192. https://doi.org/10.3233/SHTI190209.

[19] Kerr, W. (2018). America, don't throw global talent away. $\begin{array}{llll}\text { Nature, } & 563 & \text { (7732), } & \end{array}$ https://doi.org/10.1038/d41586-018-07446-2.

[20] Kirby, D. A., Guerrero, M., \& Urbano, D. (2011). Making universities more entrepreneurial: Development of a model. Canadian Journal of Administrative Sciences, 28 (3), 302-316. https://doi.org/10.1002/CJAS.220.

[21] Nghia, T. L. H. (2019). Motivations for studying abroad and immigration intentions: The case of Vietnamese students. Journal of International Students, 9 (3), 758-776. https://doi.org/10.32674/jis.v0i0.731.

[22] Manuel, K. M. (2016, August 1). State challenges to federal enforcement of immigration law: From the mid-1990s to the present. 7-5700, www.crs.gov, R43839.

[23] Mazzarol, T., \& Soutar, G. N. (2002). "Push-pull" factors influencing international student destination choice. International Journal of Educational Management, 16 (2), 8290. https://doi.org/10.1108/09513540210418403. 
[24] Pande, A., Tigau, C., \& Yuan, Y. (2017). Skilled immigration and the conditions of labour competition in the US: A comparative study of the Indian, the Mexican and the Chinese diasporas. Migration and Development, 6 (3), 343-354. https://doi.org/10.1080/17415977.2017.1301044.

[25] Redden, E. (2017a, September 5). Some universities are reporting declines in international enrollments, ranging from modest to substantial. Inside Higher Ed. Retrieved February 15 2020 ,

from https://www.insidehighered.com/news/2017/09/05/some-univ ersities-are-reporting-declines-international-enrollments-rangi ng-modest.

[26] Redden, E. (2017b, November 13). U.S. universities report declines in enrollments of new international students; study abroad participation increases. Inside Higher Ed. Retrieved February 15, 2020, from https://www.insidehighered.com/news/2017/11/13/us-universi ties-report-declines-enrollments-new-international-students-st udy-abroad.

[27] Riaño, Y., Van Mol, C., \& Raghuram, P. (2018). New directions in studying policies of international student mobility and migration. Globalisation, Societies and Education, 16 (3), 283-294. https://doi.org/10.1080/14767724.2018.1478721.

[28] Romero, A. (2017). Immigration barriers will affect U.S. academia. www.aromerojr.net.

[29] Rose-Redwood, C., \& Rose-Redwood, R. (n. d.). Rethinking the politics of the international student experience in the age of Trump. Journal of International Students, 7 (3), I-IX Retrieved February 24, 2020, from https://doi.org/10.32674/jis.v7i3.201.

[30] Ruiz, N. K., \& Budiman, A. (2018, May 10). Increase in foreign student graduates staying and working in U.S. Pew Research Center. Retrieved February 19, 2020, from https://www.pewresearch.org/global/2018/05/10/number-of-fo reign-college-students-staying-and-working-in-u-s-after-gradu ation-surges/.

[31] Sá, C. M., \& Sabzalieva, E. (2018). The politics of the great brain race: Public policy and international student recruitment in Australia, Canada, England and the USA. Higher Education, 75 (2), 231-253. https://doi.org/10.1007/s10734-017-0133-1.
[32] Shih, K. (2017). Do international students crowd-out or cross-subsidize Americans in higher education? Journal of Public Economics, 156, 170-184. https://doi.org/10.1016/j.jpubeco.2017.10.003.

[33] Smith, C. (2016). International student success. Strategic Enrollment Management Quarterly, 4 (2), 61-73. https://doi.org/10.1002/sem3.20084.

[34] Stein, S., \& de Andreotti, V. O. (2016). Cash, competition, or charity: International students and the global imaginary. Higher Education, 72 (2), 225-239. https://doi.org/10.1007/s10734-015-9949-8.

[35] Study International Staff. (2019, July 5). University tuition fees in the US are at an all-time high. Study International News. Retrieved February 15, 2020, from https://www.studyinternational.com/news/university-tuition-fe es-in-the-us-are-at-an-all-time-high/.

[36] Stuen, E. T., Mobarak, A. M., \& Maskus, K. E. (2012). Skilled immigration and innovation: Evidence from enrolment fluctuations in US doctoral programmes. Economic Journal, $122 \quad$ (565), 1143-1176. https://doi.org/10.1111/j.1468-0297.2012.02543.x.

[37] Thompson, D. (2017, July 26) The bursting of the college bubble. The Atlantic. Retrieved February 19, 2020, from https://www.theatlantic.com/business/archive/2017/07/college -bubble-ends $/ 534915 /$.

[38] Usher. A. (2019). Has President Trump Scared Away All the Foreign Students? The facts behind fears of a higher-education revenue recession. Education Next. Retrieved February 15, 2020 , from https://www.educationnext.org/has-president-trump-scared-aw ay-foreign-students-facts-behind-fears-higher-education-reven ue-recession/.

[39] Wu, C., \& Wilkes, R. (2017). International students' post-graduation migration plans and the search for home. Geoforum, 80 https://doi.org/10.1016/j.geoforum.2017.01.015.

[40] Wu, T., \& Naidoo, V. (2016). The role of international marketing in higher education. In International marketing of higher education (pp. 3-9). Palgrave Macmillan. https://doi.org/10.1057/978-1-137-54291-5_1. 